\section{Bedside control of heparin therapy by a simple whole blood clotting method}

\author{
c. COTTON KENNEDY AND M. J. ROCKS From the \\ Haematology Department, Belfast City Hospital, \\ Belfast
}

Control of heparin therapy is most often monitored by whole blood clotting times. Based on the oldestablished method of Lee and White (1913) it is ideally carried out in the ward by a trained laboratory technician, the clotting process being allowed to occur in glass tubes, which are inverted at intervals and incubated in a portable water bath at $37^{\circ} \mathrm{C}$.

In the past few years there has been an increase in the number of patients receiving heparin for a variety of conditions. Frequently laboratory control is not sought or is not available. When it is required it is often difficult in a busy laboratory to provide a technician to cover all the demands, especially at inconvenient times. In recent years we have developed a simple, accurate method which can quickly be demonstrated to the ward doctor who, without calling on laboratory help or using a waterbath, can thereafter measure clotting times at the bedside.

\section{Method}

In the ward two standard glass tubes $(8 \mathrm{~mm} \times$ $75 \mathrm{~mm}$ ) are warmed in the hand for three minutes. Two $\mathrm{ml}$ venous blood is then withdrawn and a stopwatch is started as soon as the blood enters the syringe. One $\mathrm{ml}$ blood is dispensed into each of the two tubes. The tubes are held tightly in the hand and are inspected by tilting gently just beyond $90^{\circ}$ every 30 seconds until the blood clots. The whole blood clotting time is taken as the average time of clot formation in the two tubes.

Hand temperatures measured in our series varied from $29^{\circ} \mathrm{C}$ to $33^{\circ} \mathrm{C}$.

\section{Results}

To establish the normal range for the whole blood clotting time 100 normal subjects were selected.

The Lee and White method, using a water bath at $37^{\circ} \mathrm{C}$, and the hand temperature technique were carried out simultaneously by two independent observers and the results were compared (fig 1).

Received for publication 8 August 1973.

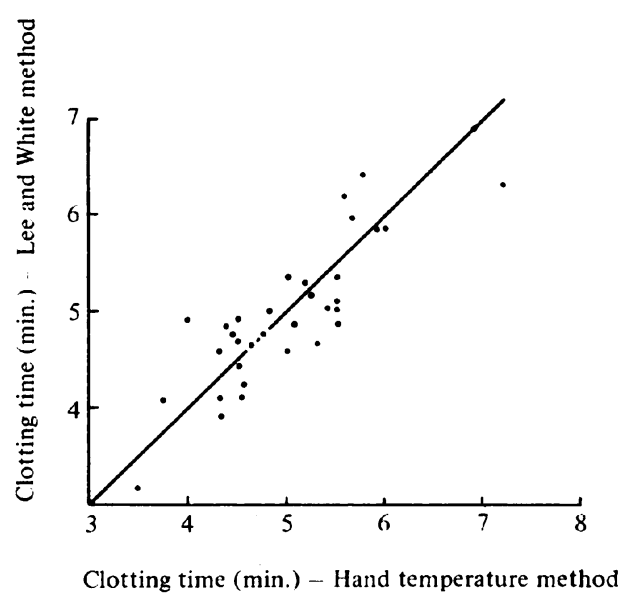

Fig 1 One hundred normal subjects. Comparison between results obtained by the method of Lee and White and the hand temperature method

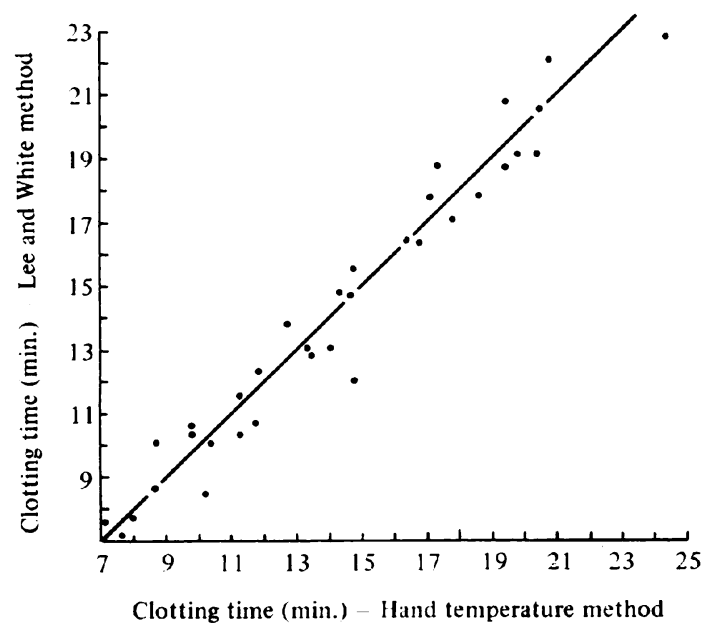

Fig 2 Whole blood clotting times on 50 patients treated with heparin

It can be seen that all the results are between three-and-a-half and seven minutes for the Lee and White method, while that of the hand temperature method is within the range of four to seven-and-ahalf minutes.

Because the normal range of both techniques was, for practical purposes, very similar we decided to carry the process a stage further by testing patients who were receiving intravenous or subcutaneous 
heparin therapy, again using both whole blood clotting methods simultaneously. The results obtained are shown in figure 2 .

\section{Comment}

Substitution of the hand temperature technique for that of the water bath method has enabled ward doctors, unused to performing coagulation tests, to measure accurately clotting times at the bedside.

We stress that brief instruction from trained laboratory staff should be given on the first occasion.

According to our findings hand temperatures, several degrees below $37^{\circ} \mathrm{C}$, make little difference to whole blood clotting times. Based on our results of the Lee and White method at $37^{\circ} \mathrm{C}$ and the handheld method at lower temperatures, we regard the normal whole blood clotting time by the latter technique to be between four and seven-and-a half minutes.

We thank our medical and technical colleagues at the Belfast City Hospital for their cooperation and Miss E. Mullan, who typzd this paper.

\section{Reference}

Lee, R. I., and White, P. D. (1913). A clinical study of the coagulation time of blood. Amer. J. med. Sci., 145, 495-503.

\section{Letters to the Editor}

\section{Candida Infections}

The paper by Stieritz, Law, and Holder (J. clin. Path., 1973, 26, 405-408) states that all Candida isolates from patients should be speciated. Isolation of Candida species representing colonization of skin and mucous membranes occurs daily in most clinical laboratories. It is our experience that less than $1 \%$ of these are associated with infection with this genus. Although isolation from blood and urine is more suggestive of infection, many of these prove to be transient or spurious.

Continued study of the relative pathogenicity and antimicrobial susceptibility of Candida species is desirable. This may be accomplished in the majority of hospitals by referring isolates, which are repeatedly isolated from patients with symptoms suggesting infection, to reference laboratories which maintain the skill and materials required for accurate speciation. Despite acknowledged differences in the pathogenicity of Candida species, all may produce fatal systemic infections. The decision to treat should be based on clinical evidence of infection, not the species isolated. It is academically satisfying to have speciation but it is not essential to diagnosis and treatment. Laboratory workers and those responsible for licensure and performance evaluation may infer from these authors' remarks need and justification for new minimum laboratory standards. Increasing public reaction to rising health care costs dictates that we give greater attention to the cost benefit of arbitrary often academically inspired recommendations for increasingly expensive clinical microbiology.

RAYMOND C. BARTLETT Division of Microbiology, Department of Pathology, Hartford Hospital, Hartford, Conn., USA

\section{Klebsiella Species in Chest Infections}

I read with interest Dr Fallon's (J. Clin. Path, 26, 253) re-assessment of the significance of Klebsiella species in chest infections and note that he confirms the difference in this respect between $K$. aerogenes and other species.

May I make the following observations?

1 Now that digestion-dilution methods are widely employed to avoid deceptive false positive cultures in sputum bacteriology (Wilson and Martin, 1972), I doubt the wisdom of culturing centrifuged deposits of sputum, other than for fungal isolations. This will have the effect of concentrating small numbers of coliforms, which will overgrow the mixed normal flora but would have been clearly identified as of doubtful significance by routine techniques. Though it may be quibbling, in many instanc probably overemphasizes the importas of coliforms in sputum to talk of socon ary invasion. Their invasive poten are nil in patients with normal imi mechanisms. Secondary coloniza五延 probably a truer assessment of their significance.

2 I think that 10 years on one cap longer recommend a return to eponyna titles such as Friedlander's bact. Perhaps a satisfactory compromise wi? be the term 'respiratory Klebsiella's. used in the current edition of Topley Wilson.

J. H. DAREH Royal Postgraduate Medical Sch Hammersmith Hospixi: Lo를

\section{Reference}

Wilson, M. J. B and Martin, D. E Quantitative sputum culture as a mea.! excluding false positive reports in the rovi microbiology laboratory. J. clin. PathCS 697.701. 